\title{
Anatomic variation of the right hepatic artery during laparoscopic cholecystectomy
}

\author{
Faik Tatlı,' (1) Mehmet Gümer, ${ }^{1}$ (1) Fırat Erkmen, ${ }^{1}$ (1) Uğur Ekici, \\ ๑ Osman Bardakçı,' ${ }^{1}$ Orhan Gözeneli' \\ 'Department of General Surgery, Harran University Faculty of Medicine, Şanlıurfa, Turkey \\ ${ }^{2}$ Department of General Surgery, İstanbul Gelişim University Faculty of Medicine, İstanbul, Turkey
}

\section{To The Editor;}

Laparoscopic cholecystectomy has many advantages such as less postoperative pain, better cosmetic results, shorter hospital stay, and earlier time to return to work. Although it is a very frequent operation today, complications can be seen in some cases even in experienced hands. These can be life-threatening complications such as biliary tract injuries and vascular injuries. Hepatic artery related injuries are the primary vascular injuries. Vascular injuries are usually seen together with biliary tract injuries, but they can also occur as isolated vascular injuries. Such injuries may occur due to inappropriate dissection as well as vascular variations.

The present study aims to present the right hepatic artery variation during surgery in 2 patients undergoing laparoscopic cholecystectomy due to cholelithiasis.

\section{Cases}

Case 1: A 44-year-old male patient applied with the clinical picture of gallbladder stone. The hepatobiliary ultrasonography revealed that there was a $2 \mathrm{~cm}$ stone in the gallbladder. The patient was taken into the operation with the diagnosis of cholelithiasis. The operation was started laparoscopically and with standard 4 trocars. The gallbladder wall had a minimal edema. During the Callot dissection, the right hepatic artery was moving upwards under the gallbladder peritoneum at the medial part of the gallbladder. It was seen that the artery was left from the gallbladder and entered into the liver in the medial part of the gallbladder bed at about 4-5 cm distance (Fig. 1). When dissected, the artery was seen to be giving branches to the gallbladder in the upper part. These branches were isolated one by one and clipped on and the right hepatic artery was preserved. Then the standard cholecystectomy was performed. There was no problem in the postoperative follow-up and the patient was discharged on the second day.

Case 2: A 51-year-old female patient applied with dyspeptic complaints. The hepatobiliary ultrasonography revealed that there was a $1.2 \mathrm{~cm}$ stone in the gallbladder. The operation was started laparoscopically and with standard 4 trocars. The Callot triangle dissection revealed that the right hepatic artery continued in the medial region of the gallbladder and gave a cystic artery branch at about 2-3 $\mathrm{cm}$ proximal. The cystic artery was isolated and clipped on. It was observed that the artery entered the liver from the medial of the gallbladder and about $3-4 \mathrm{~cm}$ proximal to the callot triangle after being isolated (Fig. 2). The operation was completed by the standard cholecystectomy. There was no problem in the postoperative follow-up and the patient was discharged on the second day. 

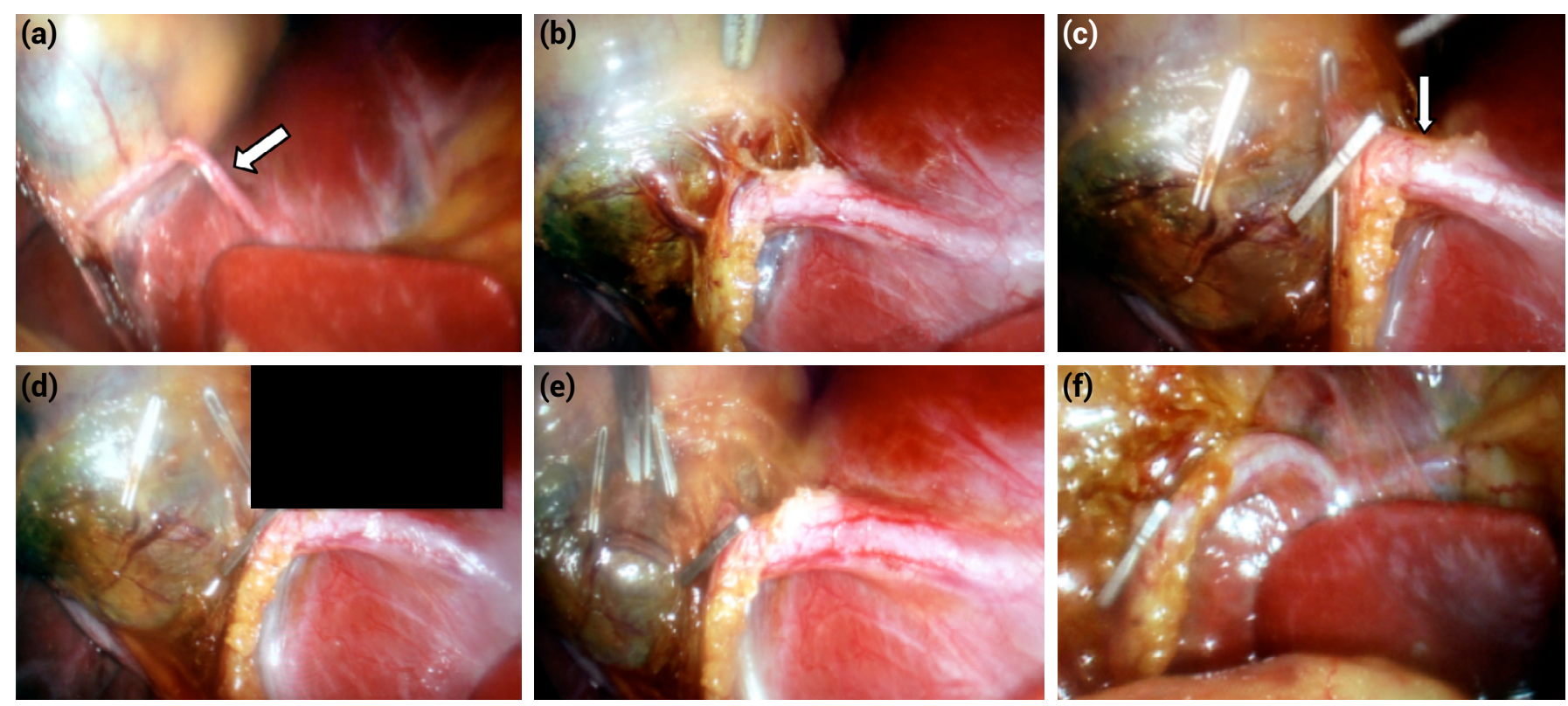

Figure 1. (a-f) The artery was left from the gallbladder and entered into the liver in the medial part of the gallbladder bed at about $4-5 \mathrm{~cm}$ distance.

Today, laparoscopic cholecystectomy is accepted as the gold standard in the treatment of cholelithiasis. ${ }^{[1]}$ Although it is a very frequent operation, complications can be seen in some cases even in experienced hands. These can be life-threatening complications such as biliary tract injuries and vascular injuries. In the literature, the rates of biliary tract injury are between $0.8 \%$ and $1.4 \%,{ }^{[2]}$ while the rates of hepatic artery injuries are between $7 \%$ and $32 \% .^{[3,4]}$

Despite it is currently used in the treatment of many diseases, the laparoscopic surgery involves many complications from the first day that it began to be used until today. The common biliary tract injuries and many other complications were more frequent in the early days of laparoscopic cholecystectomy. The reason for this was that the surgeons had a difficult learning curve at the beginning. Despite the extensive skills and experiences of surgeons, complications of this procedure are still being reported in the modern world.

Most complications that occur during laparoscopic cholecystectomy are due to anomalous dissection, anatomical variations, and the fact that anatomical structures are not revealed. It is reported that the right hepatic artery variations vary between 3-15\% during the laparoscopic cholecystectomy. ${ }^{[5,6]}$ The high number of these variations can lead to bleeding during dissection and can be seen and clipped as a cystic artery. In our study in our study, we evaluated the right hepatic artery as a cystic artery at the dissection stage and clipped it. Continuation of dis- section; we saw the artery go up and into the liver and removed the clips (Fig. 1).

In a study conducted on the hepatic artery variations, Jones et al. ${ }^{[7]}$ reported that the right hepatic artery may originate from the aorta, the gastroduodenal artery, the right gastric artery, or an artery that is normally on the left but deviated on the right when they do not leave from the arteria communis or where there is no arteria hepatica communis. Despite the right hepatic artery gets out from

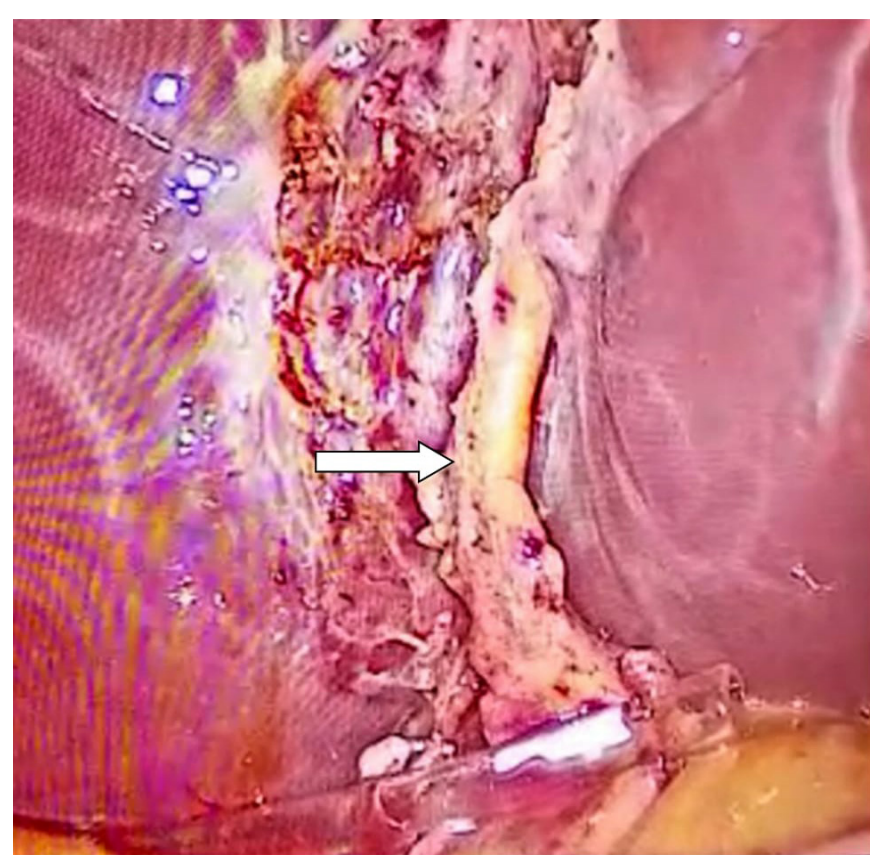

Figure 2. The artery entered the liver from the medial of the gallbladder and about $3-4 \mathrm{~cm}$ proximal to the callot triangle. 
the normal hepatica propria in the cases included in this study, it was seen to be continuing in the anterior-lateral of the main bile duct and gave branches after continuing over the gallbladder and entered the liver from an upper region.

In conclusion, the laparoscopic cholecystectomy is currently one of the most common minimal invasive surgical procedures. Anatomical variations in the formation of vascular complications during laparoscopic cholecystectomy have an important place. Anatomic variations have an important role in the formation of vascular complications during the laparoscopic cholecystectomy. Therefore, as is the case with any surgical procedure, it is important that surgeons predict possible vascular variations and obey the safe cholecystectomy criteria in order to prevent complications that may occur.

\section{References}

1. Lai EC, Yang GP, Tang CN, Yih PC, Chan OC, Li MK. Prospective randomized comparative study of single incision la- paroscopic cholecystectomy versus conventional four-port laparoscopic cholecystectomy. Am J Surg 2011;202:254-8.

2. Fletcher DR, Hobbs MS, Tan P, Valinsky LJ, Hockey RL, Pikora TJ, et al. Complications of cholecystectomy: risks of the laparoscopic approach and protective effects of operative cholangiography: a population-based study. Ann Surg 1999;229:449-57. [CrossRef]

3. Halasz NA. Cholecystectomy and hepatic artery injuries. Arch Surg 1991;126:137-8. [CrossRef]

4. Chiruvella A, Sarmiento JM, Sweeney JF, Lin E, Davis SS Jr. latrogenic combined bile duct and right hepatic artery injury during single incision laparoscopic cholecystectomy. JSLS 2010;14:268-71. [CrossRef]

5. Coşkun M, Kayahan EM, Ozbek O, Cakir B, Dalgiç A, Haberal $M$. Imaging of hepatic arterial anatomy for depicting vascular variations in living related liver transplant donor candidates with multidetector computed tomography: comparison with conventional angiography. Transplant Proc 2005;37:1070-3.

6. Abdullah SS, Mabrut JY, Garbit V, De La Roche E, Olagne E, Rode $A$, et al. Anatomical variations of the hepatic artery: study of 932 cases in liver transplantation. Surg Radiol Anat 2006;28:468-73. [CrossRef]

7. Jones RM, Hardy KJ. The hepatic artery: a reminder of surgical anatomy. J R Coll Surg Edinb 2001;46:168-70. 